\title{
DIAGNÓSTICO QUALI-QUANTITATIVO DA ARBORIZAÇÃO DAS PRINCIPAIS VIAS DO MUNICÍPIO DE CAPANEMA, PARÁ
}

\author{
QUALI-QUANTITATIVE DIAGNOSIS OF THE AFFORESTATION OF THE MAIN \\ ROADS OF CAPANEMA, PARÁ
}

\author{
Akim Afonso Garcia1, Gabriela Costa Duarte Ribeiro², Lucas Lima Raiol³, Danilo Mesquita Melo4
}

\begin{abstract}
RESUMO
No meio urbano é comum o aparecimento de problemas na arborização decorrentes da falta de planejamento. A identificação dessas adversidades é uma importante ação para prevenir eventuais problemas, proporcionando soluções que viabilizem o harmonioso convívio da vegetação junto a dinâmica urbana. Desta forma, o objetivo deste trabalho foi caracterizar a estrutura arbórea das principais vias do município de Capanema, Pará. No período de março a abril de 2019 foi analisada toda a vegetação arbórea-arbustiva distribuídas em calçadas e canteiros-centrais em 42 quarteirões das principais vias da cidade. Na pesquisa, foi investigado estas espécies em relação à distribuição, compatibilidade com a infraestrutura e qualidade arbóreo-arbustiva. De acordo com os resultados, a maioria dos indivíduos são mangueiras (Mangifera indica L.), representando 61,32\%, e 10,29\% de fícus (Ficus benjamina L.), ambas espécies exóticas ao ecossistema local. Foram identificados inúmeros conflitos das plantas com a infraestrutura urbana. Embora a cidade de Capanema esteja localizada na Amazônia, com uma grande diversidade de espécies nativas com potencial para a arborização urbana, a escolha de árvores ainda é realizada conforme a tradição cultural. É necessário a mobilização da esfera municipal para o fomento de decretos relacionados ao planejamento da arborização e melhor planejamento urbano.
\end{abstract}

Palavras-chave: Planejamento urbano; Frequência arbórea; Estrutura arbórea; Diversidade arbórea; Mangueiras.

\begin{abstract}
In urban areas, it is common to see problems in afforestation due to lack of planning. The identification of these adversities is an important action to prevent possible problems, providing solutions that enable the harmonious coexistence of vegetation along with urban dynamics. Thus, the objective of this study was to characterize the afforestation structure of the main roads in the municipality of Capanema, Pará. From March to April 2019, all trees and shrubs distributed on sidewalks and central islands in 42 blocks of the main areas was analyzed. In this research, the species were investigated in relation to distribution, compatibility with the infrastructure and tree-shrub quality. According to the results, most individuals are mango trees (Mangifera indica L.), representing $61.32 \%$, and $10.29 \%$ are ficus (Ficus benjamina L.), both species are exotic to the local ecosystem. Numerous conflicts between plants and urban infrastructure have been identified. Although the city of Capanema is located in Amazon, with a great diversity of native species with potential for urban afforestation, the choice of trees is still carried out according to cultural tradition. It is necessary to mobilize the municipal sphere to foster decrees related to afforestation planning and better urban planning.
\end{abstract}

Keywords: Urban planning; Tree frequency; Afforestation structure; Tree diversity; Mango trees

\footnotetext{
Recebido em 10.01.2020 e aceito em 14.05.2020

1 Engenheiro Agrônomo. Bacharel. Universidade Federal Rural da Amazônia. Capanema/PA. Email: akim.afonso@gmail.com 2 Engenheira Agrônoma. Mestranda. Universidade Federal Rural da Amazônia. Belém/PA. Email: gaabriiela.7@gmail.com 3 Engenheiro Ambiental. Bacharel. Universidade Federal Rural da Amazônia. Capanema/PA. Email: lucasraiolsk8@hotmail.com 4 Engenheiro Agrônomo. Doutorado. Professor, Universidade Federal Rural da Amazônia. Capanema/PA. Email: danilo.melo@ufra.edu.br
} 


\section{INTRODUÇÃO}

A floresta urbana, seja com vegetação nativa ou exótica, traz inúmeros benefícios ecológicos, climáticos ou sociopsicológicos, e, reconhecer tal estrutura e sua função econômica, social e ambiental é uma das principais ações para obtenção de um bom planejamento urbano (GRISE; BIONDI; ARAKI, 2017).

Para que a arborização forneça benefícios é importante atender as recomendações técnicas de cada espécie. Desse modo, a arborização poderá trazer benefícios ao ambiente, como, a minimização dos efeitos das ilhas de calor pelo processo fotossintético, controle da direção e velocidades dos ventos, sombreamento e redução da poluição atmosférica, sonora e visual (GONÇALVES et al., 2018).

Para Muller (2002), após o aparecimento de problemas decorrentes do plantio irregular é que surge a preocupação com a implantação adequada da vegetação arbóreo-arbustiva. Para tal, uma série de condicionantes técnicos devem ser levados em consideração antes da execução de um projeto de arborização, além dos aspectos culturais, históricos e informações pertinentes às necessidades locais.

Conforme Silva e Silveira (2020), o planejamento adequado da arborização é indispensável para obter-se um desenvolvimento urbano sustentável, buscando a qualidade ambiental e social. A qualidade ambiental é definida pela interação de diversos indicadores que apontem um espaço com condições salubres, dessa forma fornecendo condições básicas de saúde e lazer para sustentabilidade da vida humana (DUARTE et al., 2018).

Um bom planejamento da arborização deve contemplar as recomendações técnicas ao longo da implantação e desenvolvimento arbóreo-arbustivo, dessa forma podendo atingir melhorias do microclima e redução dos índices de poluição, dentre outros fatores que serão alcançados por meio de prévios estudos. Para um bom planejamento da arborização no espaço urbano é indispensável o diagnóstico das espécies plantadas, verificando os possíveis problemas e apontando soluções que possibilite um bom manejo, assim, a árvore fornecerá benefícios e não trará problemas aos equipamentos urbanos (GONÇALVES et al., 2018)

A ausência de diretrizes que promovam o harmonioso estabelecimento da arborização no espaço urbano é um dos principais fatores que levam a escolhas equivocadas de espécies incompatíveis com o ambiente, com seu uso social e econômico do espaço comprometido (SILVA; SILVEIRA, 2020).

A falta de planejamento da estrutura urbana pode ser outro fator que poderá dificultar a realização de um bom planejamento da arborização. São necessárias ações que priorizem a adaptação de vias e que forneçam espaços adequados para um crescimento arbóreo satisfatório, 
que muitas vezes são ignorados por problemas sociais, econômicos ou até mesmo por falta de conhecimento dos benefícios da arborização ao meio (DUARTE et al., 2018).

A presença das árvores no contexto urbano pode resultar em benefícios ou problemas, tanto para moradores quanto à infraestrutura urbana, assim destaca-se a importância da escolha adequada da espécie destinada a arborização, buscando o manejo entre os componentes da paisagem construída e o elemento vegetal (SOUSA et al., 2018).

Neste contexto, conhecer a estrutura arbórea de uma cidade é importante no que concerne a um futuro planejamento ou replanejamento da arborização urbana, promovendo ações de desenvolvimento urbano e paisagístico, culminando em melhorias na qualidade de vida dos habitantes.

Esse estudo teve por objetivo conhecer e caracterizar a atual estrutura arbórea das principais vias do município de Capanema-Pará, a partir da distribuição, compatibilidade com a infraestrutura e qualidade arbóreo-arbustiva.

\section{MATERIAL E MÉTODOS}

O estudo foi realizado no município de Capanema, localizado na mesorregião do nordeste paraense. O município possui cobertura vegetal formada por floresta equatorial latifoliada, mas possui extensas áreas de vegetação secundaria (Capoeira), em decorrência ao grande período de exploração ocasionado pelo processo de pecuarização na região (SILVA; SANTOS, 2006).

Segundo dados do Instituto Nacional de Meteorologia (INMET, 2018), a temperatura mínima e máxima absoluta anual da região é, respectivamente, de 16,6 e 36,6 ํㅡ, a média da umidade relativa do ar é $86,5 \%$, com precipitação acumulada anual de 2510,2 mm. As chuvas se concentram entre os meses de janeiro a junho, não se distribuindo ao longo do ano, o que implica em grandes excedentes hídricos, provocando escoamentos superficiais e aumento no nível dos rios da região (SILVA; SANTOS, 2006). O município de Capanema conta com uma superfície arborizada de 15\% (IBGE, 2010).

Neste estudo foi considerado as vias que possuíam maior fluxo de pessoas e automóveis, conforme indicadas pela secretaria de infraestrutura do município. Além disso, foi levado em consideração a importância dessas avenidas no acesso aos principais pontos de interesse na cidade (hospitais, zona comercial, entrada e saída da cidade, entre outros) totalizado um perímetro aproximado de $7 \mathrm{~km}$.

Foi analisado toda a vegetação arbórea-arbustiva distribuídas em calçadas e canteiroscentrais em 42 quarteirões, sendo: 17 quarteirões na Av. Barão de Capanema (1²11'42.46"S 
4711'25.12"O e 1'11'28.08"S 47010'11.40"O); 10 quarteirões na Av. João Paulo II (1'11'28.82"S

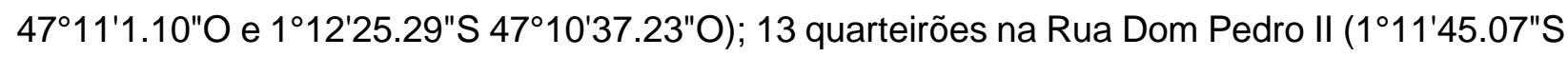
47010'53.93"O e $1^{\circ} 11^{\prime} 40.96 " S$ 47 $\left.10^{\circ} 7.81^{\prime \prime O}\right)$; e 2 quarteirões na Travessa Quatorze de Março, devido suas dimensões (1¹1'43.90"S 4710'37.26"O e 1¹2'13.98"S 47¹0'33.55"O) (Figura 1).

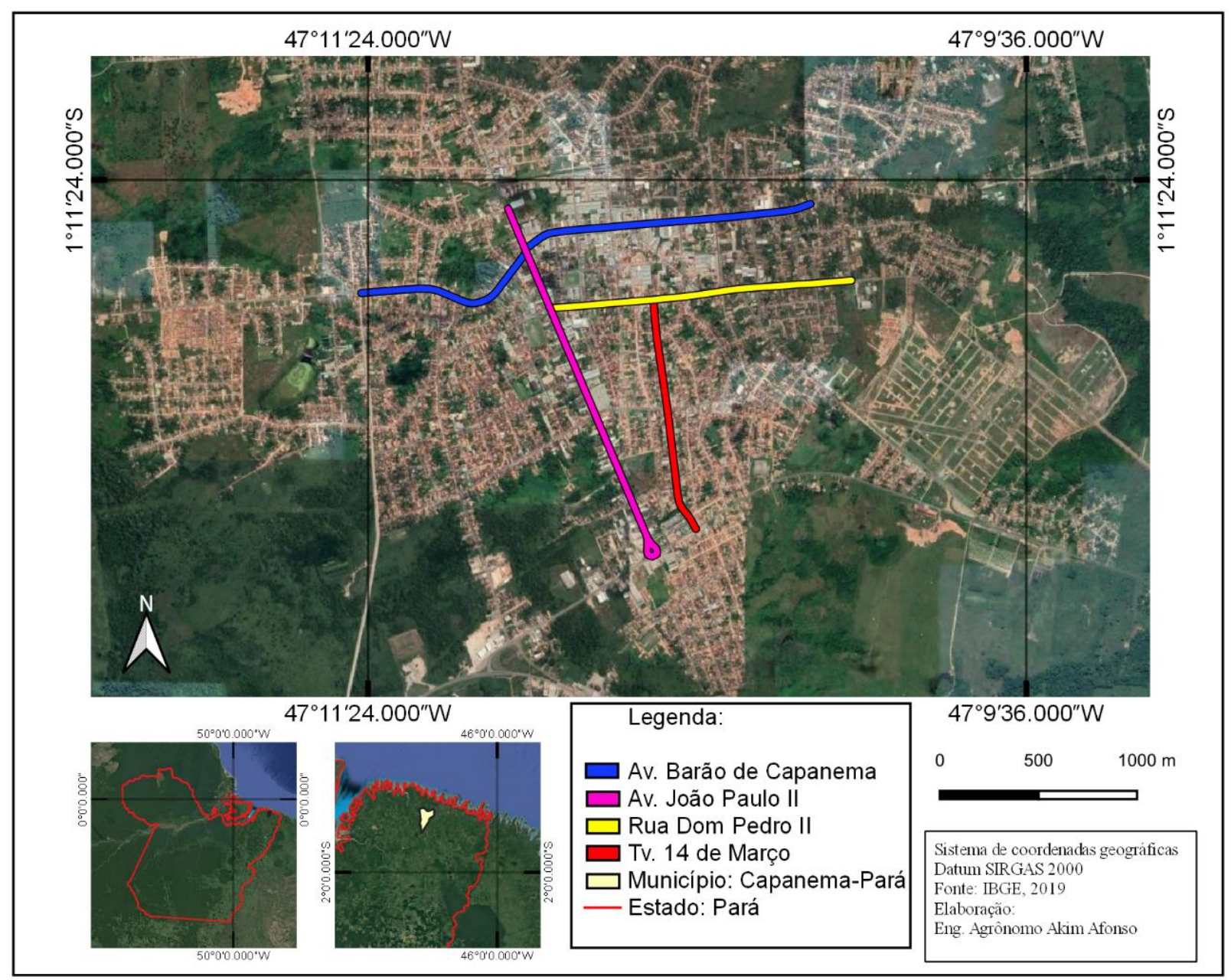

Figura 1. Área onde foi realizado o estudo, no município de Capanema-Pará. Figure 1. Area where the study was carried out, in the city of Capanema-Pará.

O trabalho de campo foi realizado no período de março a abril de 2019, possuindo caráter quali-quantitativo, sendo utilizado planilhas estruturadas com perguntas fechadas. A metodologia de coleta e análise dos dados teve como base a temática proposta por Lopo (2014), seguindo os parâmetros, características e metodologias, conforme Tabela 1. 
Tabela 1. Parâmetros adotados na investigação do diagnóstico arbóreo-arbustivo e seus métodos de análise

Table 1. Parameters adopted in the investigation of tree-shrub diagnosis and its methods of analysis

\begin{tabular}{|c|c|c|c|}
\hline $\begin{array}{l}\text { TEMÁTICA } \\
\text { ADAPTADA }\end{array}$ & PARÂMETRO & CARACTERÍSTICAS & METODOLOGIA \\
\hline DISTRIBUIÇÃO & $\begin{array}{l}\text { Localização da } \\
\text { árvore }\end{array}$ & $\begin{array}{l}\text { Áreas residenciais, comerciais ou } \\
\text { mistas }\end{array}$ & Observação in locu \\
\hline $\begin{array}{l}\text { IDENTIFICAÇÃO } \\
\text { ARBÓREO- } \\
\text { ARBUSTIVA }\end{array}$ & Identificação & $\begin{array}{l}\text { Nome popular; nome científico; } \\
\text { arbustiva ou arbórea; origem (exótica } \\
\text { ou nativa do Brasil e do ecossistema } \\
\text { regional) }\end{array}$ & $\begin{array}{c}\text { Manual de arborização de } \\
\text { Belém (PORTO; BRASIL, } \\
\text { 2013); e Flora do Brasil } \\
\text { (2020). }\end{array}$ \\
\hline \multirow{5}{*}{$\begin{array}{c}\text { COMPATIBILIDADE } \\
\text { ARBÓREA- } \\
\text { ARBUSTIVA COM } \\
\text { A } \\
\text { INFRAESTRUTURA }\end{array}$} & $\begin{array}{c}\text { Fase de } \\
\text { desenvolvimento }\end{array}$ & Jovem; adulta ou senil & $\begin{array}{l}\text { Classificação conforme } \\
\text { pesquisa }\end{array}$ \\
\hline & $\begin{array}{c}\text { Altura } \\
\text { aproximada }\end{array}$ & $\begin{array}{c}0,1 \text { a } 0,9 ; 1 \text { a } 4 ; 5 \text { a } 6 ; 7 \text { a } 10 ; \text { mais } \\
\text { de } 10 \text { metros }\end{array}$ & Observação in locu \\
\hline & Porte & $\begin{array}{c}\text { Grande porte (altura }>12,0 \text { a } 24,0 \mathrm{~m} \\
\text { e diâmetro }>16,0 \text { a } 24,0 \mathrm{~m}) ; \\
\text { Espécies de médio porte (altura }> \\
6,0 \text { a } 12,0 \mathrm{~m} \text { e diâmetro da copa }> \\
8,0 \text { a } 16,0 \mathrm{~m}) ; \text { Espécies de pequeno } \\
\text { porte (altura }>3,0 \text { a } 6,0 \mathrm{~m} \text { e diâmetro } \\
\text { de copa }>2,0 \text { a } 8,0 \mathrm{~m}) ; \text { Arbustos ou } \\
\text { arvoretas (altura } \mathrm{h}>3,0 \mathrm{~m} \text { e diâmetro } \\
\text { de copa }>2,0 \mathrm{~m})\end{array}$ & $\begin{array}{c}\text { Manual de arborização de } \\
\text { Belém (PORTO; BRASIL, } \\
\text { 2013) }\end{array}$ \\
\hline & $\begin{array}{c}\text { Altura da } \\
\text { primeira } \\
\text { bifurcação }\end{array}$ & $\begin{array}{c}0,1 \text { a } 0,9 ; 1 \text { a } 2,4 ; 2,5 \text { a } 4,5 ; \text { acima de } \\
4,6 \text { metros. }\end{array}$ & \\
\hline & $\begin{array}{l}\text { Conflitos com a } \\
\text { infraestrutura }\end{array}$ & $\begin{array}{c}\text { Conflito com fiação elétrica; } \\
\text { conflitos com edificações; } \\
\text { sinalização de trânsito; copa baixa } \\
\text { impedindo tráfego de carros ou a } \\
\text { passagem na calçada; } \\
\text { conflitos com outras árvores; e } \\
\text { interferências na visão da esquina. }\end{array}$ & Observação in locu \\
\hline \multirow{6}{*}{$\begin{array}{l}\text { QUALIDADE } \\
\text { ARBÓREO- } \\
\text { ARBUSTIVA }\end{array}$} & Manutenções & $\begin{array}{l}\text { Sinais de poda ou } \\
\text { Necessidade de poda. }\end{array}$ & ABNT NBR 16246-1:2013 \\
\hline & $\begin{array}{l}\text { Estado do } \\
\text { tronco }\end{array}$ & $\begin{array}{l}\text { Com ou sem inclinação; } \\
\text { Interferindo ou não na infraestrutura. }\end{array}$ & \multirow{4}{*}{ Observação in locu } \\
\hline & $\begin{array}{l}\text { Estado das } \\
\text { raízes }\end{array}$ & $\begin{array}{l}\text { Sem afloramento; } \\
\text { Com afloramento (calçada, guia, } \\
\text { muro/prédio, pista de rolamento). }\end{array}$ & \\
\hline & \multirow{2}{*}{$\begin{array}{l}\text { Estado do } \\
\text { canteiro }\end{array}$} & $\begin{array}{l}\text { Com espaço livre suficiente ou } \\
\text { insuficiente para o crescimento }\end{array}$ & \\
\hline & & $\begin{array}{l}\text { Presença ou ausência de } \\
\text { pavimentação (concreto) }\end{array}$ & \\
\hline & Fitossanidade & $\begin{array}{l}\text { Se possui vigor ou está } \\
\text { comprometida por adversidades; } \\
\text { Presença de cupim; } \\
\text { Insetos sugadores; } \\
\text { Ervas de passarinho; } \\
\text { Ferrugem; } \\
\text { Lagartas; } \\
\text { Broca; } \\
\text { Se possui mancha nas folhas; } \\
\text { Se possui brotação epicórmica; }\end{array}$ & Observação in locu \\
\hline
\end{tabular}

O município não apresenta planos de zoneamento, sendo utilizada utilizado para essa pesquisa a seguinte classificação: se houvesse somente estabelecimentos comerciais era 
considerado área comercial, o mesmo era definido para áreas residenciais, foi considerado áreas mistas os quarteirões que apresentassem imóveis comerciais e residenciais.

As informações técnicas acerca do ecossistema urbano local, diversidade das espécies nativas e recomendações de espécies exóticas, foi consultado em Porto e Brasil (2013), as classificações referentes a identificação das espécies e sua origem foram realizadas por meio do banco de dados da Flora do Brasil (2020).

A fase de desenvolvimento das árvores foi identificada a partir dos levantamentos realizados junto aos moradores da rua em que se localizava os vegetais, dados fornecidos pela gestão pública e observação das características morfológicas de cada espécie. Para complementação desses dados também foi utilizado imagens de satélite do Google Earth de diferentes anos para melhor aferição das informações e consultas realizadas junto aos órgãos públicos locais.

As medições e outras características avaliada in locu, seguiram as recomendações adaptadas de Lopo (2014). Para avaliação da altura aproximada foi utilizado como referência postes e outros equipamentos urbanos de altura conhecida. Para alturas até 2 metros e para medição da altura da primeira bifurcação houve auxilio da fita métrica. Na compatibilidade arbórea-arbustiva com a estrutura foi observado as interferências do meio aos indivíduos e as interferências destes no meio.

Para avaliação do vigor da espécie foi avaliado alguns parâmetros, como: cor e tamanho das folhas; densidade da copa; crescimento do broto; textura e brilho da casca do tronco e galhos (ABNT, 2013).

Os dados coletados foram inseridos em planilhas impressas especificas, para a compilação, processamento e representação gráfica dos dados foi utilizado o software Microsoft Excel 2016.

\section{RESULTADOS E DISCUSSÃO}

\section{Distribuição}

Por meio da coleta de dados foi identificado que $83,33 \%$ dos quarteirões investigados possuíam árvores ou arbustos e 16,66\% não apresentavam vegetação arbóreo-arbustiva. Grande parte dessas árvores estão distribuídas na Av. Barão de Capanema (53,90\%) e na Av. João Paulo II (32,51\%), vias que concentram o centro comercial do município, apresentando maior fluxo de automóveis e pessoas. Da mesma forma foi identificado que $43,80 \%$ das árvores e arbustos se encontravam em área comercial, 23,14\% em área mista (comercial e residencial) e 33,06\% em áreas residenciais. 
Ao longo do período da coleta dos dados houve a retirada de árvores e arbustos por iniciativa da governança municipal em vários pontos já amostrados na pesquisa, a retirada é justificada pelo órgão à custa da implantação do novo projeto de revitalização, as remoções não foram atualizadas na amostragem.

\section{Identificação arbóreo-arbustiva}

Foram catalogados 243 árvores, arbustos e palmeiras, sendo observado um total de 0,82\% de plantas arbustivas e 99,17\% árvores, e 8 famílias. Em relação à origem das espécies, foi identificado que $81,48 \%$ das árvores eram exóticas do Brasil e 18,51\% eram nativas do Brasil. As espécies mais expressivas na pesquisa foram: Mangifera indica L. (Figura 2), representando $61,32 \%$, seguido de Ficus benjamina L. com 10,29\%, Senna siamea (Lam.) H.S. Irwin \& Barneby com 7,41\%, Roystonea oleracea (Jacq.) O.F.Cook com 7,00\% e Terminalia catappa L. com $4,12 \%$ (Tabela 2).

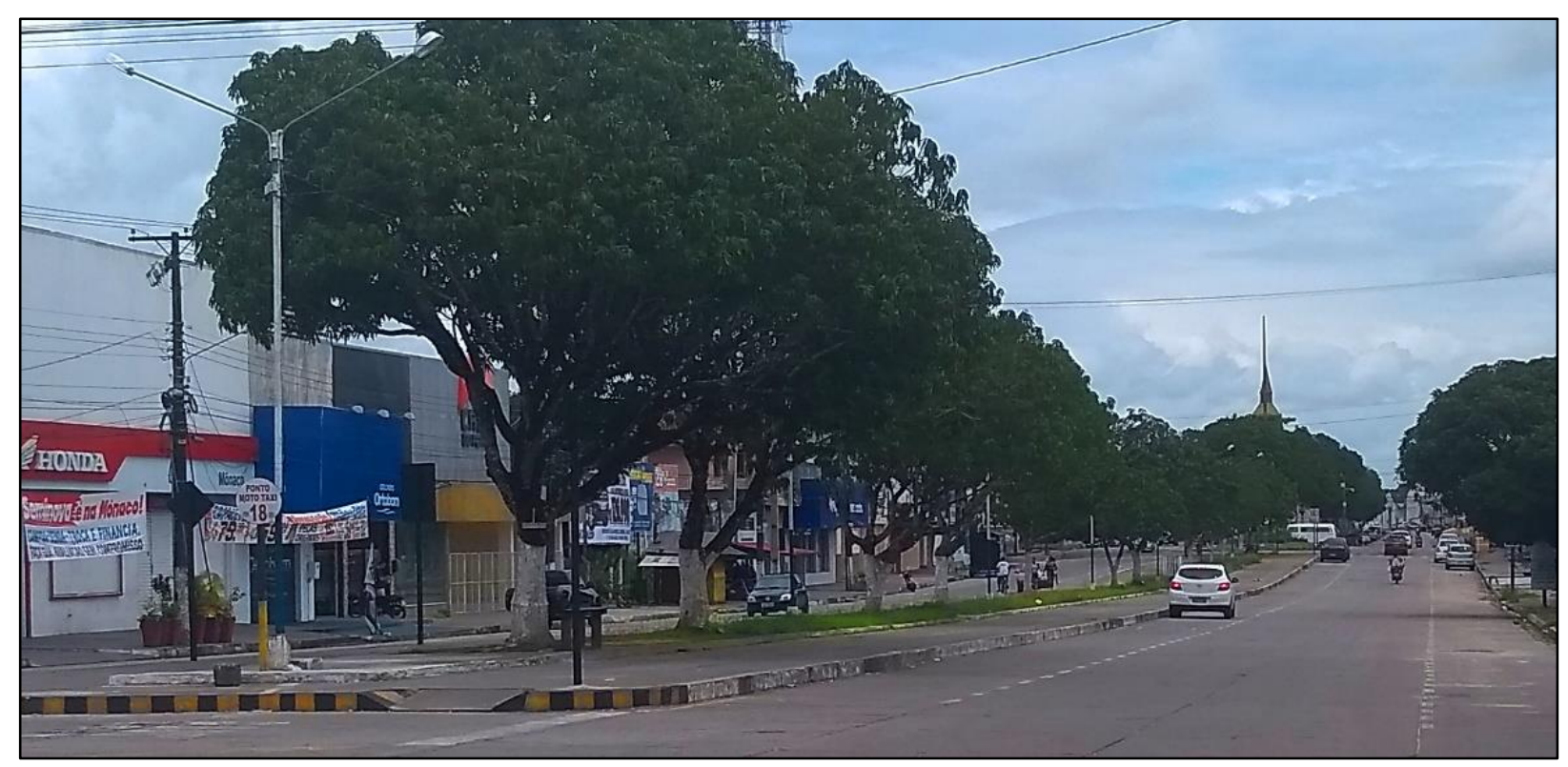

Figura 2. Mangueiras plantadas em canteiro central na Av. Barão de Capanema Figure 2. Mango trees planted in a central island at Barão de Capanema Avenue

No Brasil, a arborização urbana segue com inúmeras lacunas, e, a falta de atenção da governança é uma das principais causas que sinaliza uma importante falha no sistema de planejamento (DUARTE et al, 2018).

Foi observado que $88,47 \%$ das espécies catalogadas na pesquisa são exóticas ao ecossistema do Pará e apenas 11,53\% são nativas do ecossistema (FLORA DO BRASIL, 2020). Apesar da literatura alertar sobre os efeitos da introdução de espécies exóticas (RUFINO; SILVINO; MORO, 2019; MULLER, 2002; PORTO; BRASIL, 2013), pouco se conhece sobre os efeitos dessas espécies na Amazônia Legal (SILVA; FORSBERG, 2015). 
Tabela 2. Perfil arbóreo-arbustivo das principais vias do município de Capanema-Pará Table 2. Tree-shrub profile of the main roads in the municipality of Capanema-Pará

\begin{tabular}{|c|c|c|c|c|c|c|}
\hline Nome científico $\left({ }^{\star}\right)$ & Nome pop. $\left(^{\star}\right)$ & Origem $\left({ }^{\star}\right)$ & № & Porte & Hábito & F.r (\%) \\
\hline \multicolumn{7}{|l|}{ Família Anacardiaceae } \\
\hline Mangifera indica L. & Mangueira & ExBR & 149 & Grande & Arbóreo & $61,32 \%$ \\
\hline \multicolumn{7}{|l|}{ Família Arecaceae } \\
\hline Bismarckia nobilis Hildebr. \& H.Wendl. & Palmeira azul & ExBR & 2 & Grande & Arbóreo & $0,82 \%$ \\
\hline Roystonea oleracea (Jacq.) O.F.Cook & $\begin{array}{l}\text { Palmeira } \\
\text { Imperial }\end{array}$ & ExBR & 17 & Grande & Arbóreo & $7,00 \%$ \\
\hline \multicolumn{7}{|l|}{ Família Caricaceae } \\
\hline Carica papaya L. & Mamoeiro & ExBR & 2 & Médio & Arbustivo & $0,82 \%$ \\
\hline \multicolumn{7}{|l|}{ Família Chrysobalanaceae } \\
\hline Licania tomentosa (Benth.) Fritsch & Oiti & NaBR/ExPA & 13 & Médio & Arbóreo & $5,35 \%$ \\
\hline \multicolumn{7}{|l|}{ Família Combretaceae } \\
\hline Terminalia catappa L. & Castanhola & $\mathrm{NaBR} / \mathrm{NaPA}$ & 10 & Grande & Arbóreo & $4,12 \%$ \\
\hline \multicolumn{7}{|l|}{ Família Fabaceae } \\
\hline Senna siamea (Lam.) H.S.Irwin \& Barneby & Acácia de Sião & $\mathrm{NaBR} / \mathrm{NaPA}$ & 18 & Médio & Arbóreo & $7,41 \%$ \\
\hline Erythrina variegata L. & Brasileirinho & $\mathrm{NaBR} / \mathrm{ExPA}$ & 2 & Médio & Arbóreo & $0,82 \%$ \\
\hline Delonix regia (bojer ex hook.) raf & Flamboyant & ExóticaBR & 3 & Grande & Arbóreo & $1,23 \%$ \\
\hline \multicolumn{7}{|l|}{ Família Moraceae } \\
\hline Ficus benjamina L. & Fícus & ExBR & 25 & Grande & Arbóreo & $10,29 \%$ \\
\hline \multicolumn{7}{|l|}{ Família Nyctaginaceae } \\
\hline Bougainvillea glabra Choisy & Primavera & $\mathrm{NaBR} / \mathrm{ExPA}$ & 2 & Médio & Arbustivo & $0,82 \%$ \\
\hline TOTAIS & & & 243 & & & $100 \%$ \\
\hline
\end{tabular}

Nota: $\left(^{*}\right)=$ dados de Flora do Brasil (2020); NaBR= nativa do Brasil; ExBR= exótica do Brasil; NaPA= nativa do Pará; ExPA= exótica do Pará; №= Quantitativo catalogado; Fr= Frequência relativa;

Para Hoppen et al. (2015), uma das principais causas que levam a escolhas equivocadas das árvores destinadas a arborização é o desconhecimento das normas e da legislação vigente, principalmente pelas gestões municipais, e com isso, inúmeras espécies são introduzidas no ambiente, podendo ocasionar riscos a vegetação nativa.

Como constatado por Rufino, Silvino e Moro (2019), é um hábito comum em várias cidades brasileiras a introdução de espécies exóticas na arborização urbana, e esses hábitos também são discutidos por Muller (2002), que questiona a falta de informação sobre o desenvolvimento de árvores nativas dentro do ambiente urbano, levando a população e serviços públicos a implantarem, em muitos casos, árvores de natureza exótica.

A inclusão de espécies nativas é um importante elemento que deve estar presente na constituição de um projeto de arborização, pois além das finalidades paisagísticas a vegetação deve estar em equilíbrio com a fauna local (PAIVA, 2019).

Espécies exóticas também oferecem benefícios a fauna local, mas sua frequência poderá ocasionar desequilíbrios no ambiente. Porto e Brasil (2013) recomendam que a frequência de cada espécie no total da arborização não ultrapasse $15 \%$. Com isso, é valido 
considerar a frequência da arborização exótica ao longo do planejamento de um projeto de arborização.

O mesmo autor recomenda algumas espécies de grande, médio e pequeno porte de origem exótica, dentre elas: Delonix regia; Pinus caribea var. hondurensis (Pinho tropical); Tamarindus indica L. (Tamarindo); Senna siamea; Handroanthus roseo-alba (Ridl.) Sandwith (Ipê branco); Plumeria rubra L. e P. alba L. (Jasmim-manga); Bauhinia variegata L. (Pata-de-vaca).

O fícus representou $10,29 \%$ dos indivíduos catalogados. A espécie se apresentou como prejudicial à infraestrutura viária, causando problemas em calçadas e em redes de fiação aéreas.

Porto e Brasil (2013) e Motter e Müller (2012) comentam que a espécie apresenta inúmeros problemas ao meio urbano, pois possui um sistema radicular agressivo causando inúmeros problemas, além disso, os autores recomendam ainda a não utilização ou remoção do fícus do ambiente urbano.

Na Figura 3a é possível observar a espécie localizada na Av. João Paulo II, onde é possível notar técnicas de topiaria, característica que estimula o uso desta espécie. Na figura 3b foi utilizado a técnica empírica de pavimentação da calçada para conter os danos ocasionados pelas raízes. A falta de diretrizes na legislação do município de Capanema-Pará acaba abrindo precedentes para que continuem utilizando a espécie em vias inapropriadas para o seu plantio.
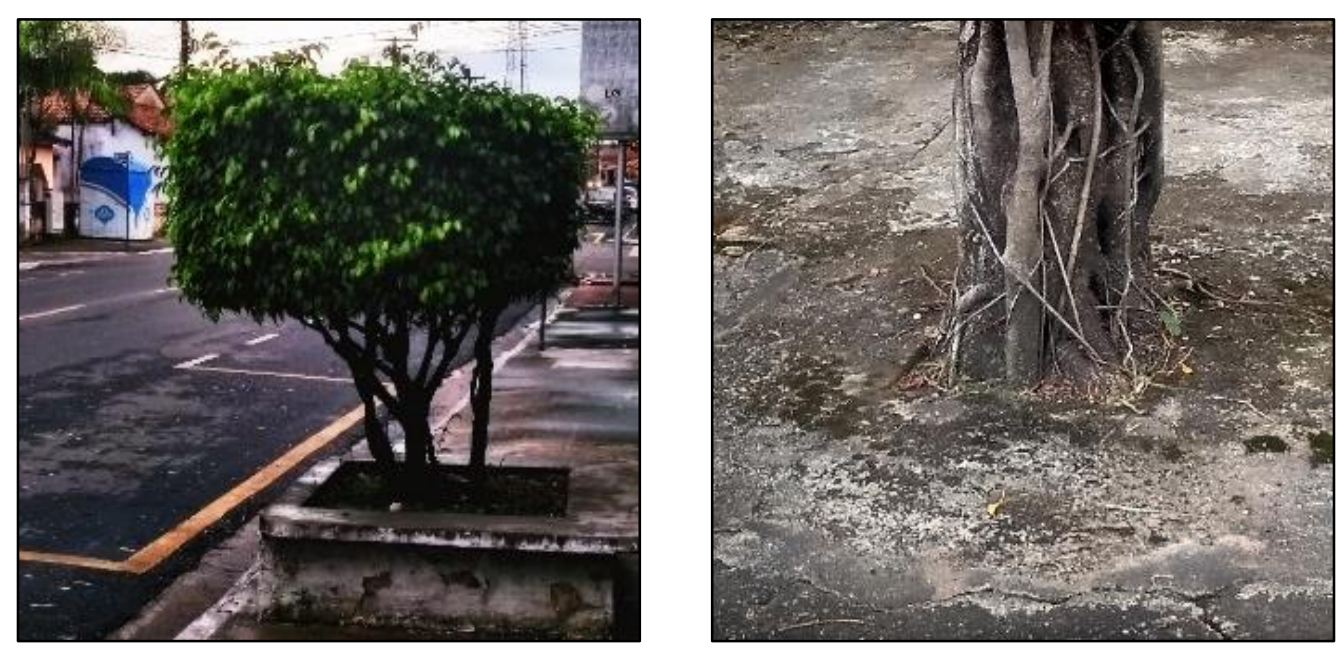

Figura 3. (a) Fícus com técnicas de topiaria. (b) Fícus com aplicação de técnica empírica de pavimentação.

Figure 3. (a) Ficus with topiary techniques. (b) Ficus with application of empirical paving technique.

Foi observado que a frequência das espécies frutíferas é de aproximadamente 75,30\%, representando quase a totalidade de espécies catalogadas. Apesar dos benefícios apontados pela presença de árvores frutíferas no meio urbano, Barros, Guilherme e Carvalho (2010) comentam os riscos decorrentes da implantação de tais espécies em vias públicas, como a 
queda de frutos volumosos, que podem ocasionar danos em edificações e veículos, e principalmente aos pedestres.

Para Biagolini e Lourenço (2018) as espécies frutíferas são recomendadas por proporcionar a atração da fauna silvestre e garantem a alimentação da ornitofauna no meio urbano. O uso de espécies frutíferas poderá beneficiar as aves que disseminarão as sementes, e à população que poderá consumir os frutos in natura (RABELO et al., 2019).

Foi identificado a presença de mamoeiro (Figura 4). Além dos plantios, os mamoeiros surgem de forma espontânea pela cidade por meio da dispersão de sementes realizadas pela fauna.

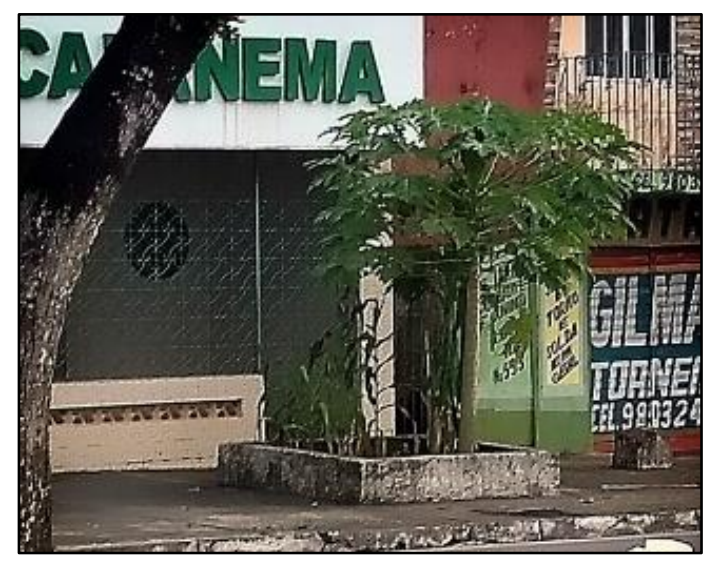

Figura 4. Plantio de mamoeiro realizado na Av. João Paulo II, Capanema-Pará Figure 4. Papaya planting carried out at João Paulo II Avenue, Capanema-Pará

Culturalmente a região possui preferência pela mangueira (PORTO; BRASIL, 2013). Das espécies catalogadas a mangueira corresponde a 61,32\%, representando mais da metade das espécies cadastradas na pesquisa, repetindo a preferência pela espécie na região (PORTO; BRASIL, 2013).

\section{Mangueiras: construção da sua preferência e importância histórica}

A importância histórica da espécie para a região começou a ser construída no governo do Superintendente Antônio José Lemos, que em seus relatórios de 1897 a 1902 apresentado ao Conselho Municipal de Belém indica a mangueira para a arborização e descreve a espécie como mais adequada para o desenvolvimento no meio urbano (LEMOS, 1903).

O superintendente Antônio Lemos citou em vários trechos de seu relatório a importância da arborização para os planos de urbanização de Belém, registro fundamentado em grandes naturalistas que visitaram a Amazônia no período, como Henry Walter Bates, que em viagens à Amazônia na busca de material zoológico e botânico ao Museu de História Natural de Londres, exaltava a importância da espécie para a região (LEMOS, 1903). 
Vislumbrado com tamanhos benefícios ao meio urbano, o Superintendente Antônio Lemos descreve em seu relatório a superioridade da mangueira:

\begin{abstract}
"Estou hoje convencido da superioridade da mangueira, - a arvore clássica de nossos antepassados, cujas qualidades são numerosas. Com efeito, desenvolve-se com rapidez, cresce a alturas consideráveis e esgalha com regularidade. Mas a todas estas vantagens, a mangueira allia ainda as de uma folhagem densa e constantemente renovada. Sua sombra é ampla e perfeita. Foi por isso que, entre ordens por mim dadas ultimamente no Horto municipal, salienta-se a recommendação para o cultivo, em grande escala, de mangueiras destinadas á arborisação, de preferencia a quaisquer outras arvores. (Lemos, 1903, p. 200)"
\end{abstract}

Vários registros do período, principalmente de naturalistas, citam as mangueiras como uma excelente espécie para arborização. Mas um dos grandes marcos veio com o governo de Antônio Lemos, que não só implantou novas mangueiras e fez do Horto um espaço para larga produção do vegetal, mas realizou a substituição de árvores nativas para a implantação de mangueiras (LEMOS, 1903).

A preferência cultural sem apoio nas recomendações técnicas pode ser um fator que gere problemas à infraestrutura. Das espécies catalogadas nesta pesquisa $23,36 \%$ eram mudas e todas elas eram de mangueiras, implantadas em um espaçamento inferior ao recomendado (PORTO; BRASIL, 2013).

Como visto, a escolha cultural das mangueiras para a arborização urbana ainda se repete pela governança na região, e inúmeros fatores podem ser apontados para esta escolha, porém é importante avaliar o local e a frequência dessa espécie, e ainda adotar um espaçamento de 3 metros para que se tenha um desenvolvimento adequado (PORTO; BRASIL, 2013).

\title{
Compatibilidade arbórea-arbustiva com a infraestrutura
}

Em relação a fase desenvolvimento do vegetal notou-se que $45,87 \%$ dos vegetais são senis, $30,58 \%$ são jovens e $23,55 \%$ são adultos. Considerando a diversidade das espécies estudadas, a maioria são de grande porte $(69,01 \%)$, seguido de $30,58 \%$ de porte médio e apenas $0,41 \%$ das espécies são de pequeno porte.

A maioria dos indivíduos avaliados possuem de 1 a 4 metros (48,76\%), seguido de 5 a 6 metros (35,95\%), 0,1 a 0,9 (11,98\%) e 7 a 10 metros (3,31\%). A altura da primeira bifurcação mais comum é de 1 a 2,4 metros (72,31\%), seguida de 0,1 a 0,9 metros (18,18\%), 2,5 a 4,5 metros $(8,68 \%)$ e acima de 4,5 (0,83\%).

Em relação aos conflitos das árvores com a infraestrutura foi observado que $14,88 \%$ estavam em conflitos com fios de baixa tensão e 1,65\% com fios de alta tensão. Os conflitos com fios de baixa tensão foi em decorrência da implantação de luminárias de até 3 metros nos canteiros centrais das avenidas, que tiveram suas ligações realizadas de forma improvisada pela 
parte aérea, utilizando os galhos de arvores como apoio da fiação. Os conflitos com fios de alta tensão foram ocasionados pela implantação de arvores de grande porte sob fiações de redes de energia e telefone (Figura 5).

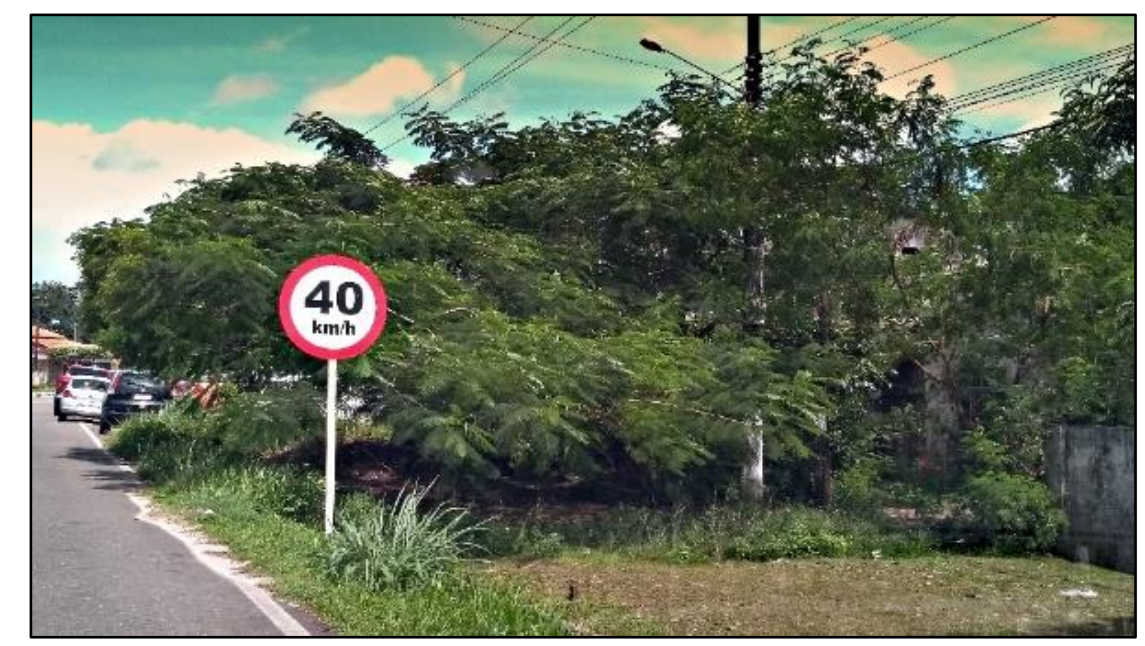

Figura 5. Árvores em conflito com a fiação e o poste de energia

Figure 5. Trees in conflict with wiring and power pole

Além dos conflitos com a rede elétrica outros problemas foram identificados, como: copa baixa, impedindo o tráfego de pessoas (6,58\%); obstrução da sinalização de trânsito $(3,70 \%)$; conflito com outras árvores (2,88\%); obstrução na visão da esquina (2,46\%); obstrução de luminárias (2,05\%); e conflito com edificações (1,23\%).

Nota-se, portanto, que há uma predominância de árvores de grande porte e que provocam conflitos com a infraestrutura urbana. Essas árvores são plantadas de forma deliberada em canteiros de até 0,5 metros, abaixo do recomentado para as espécies (PORTO; BRASIL, 2013), causando estrangulamento e danos a infraestrutura. Apesar da existência desses problemas, foi notado que são realizadas podas nessas árvores, reduzindo sua altura e a largura da copa, tentando adapta-las aos equipamentos urbanos.

A altura da primeira bifurcação mais expressivas foi de 1 a 2,4 e 0,1 a 0,9 metros, recomenda-se que a altura mínima para primeira bifurcação seja de 1,80 metros. Nas vias notase problemas em relação a grande quantidade de bifurcação baixa, atrapalhando a passagem de pedestres e de veículos em alguns casos.

Os problemas citados podem ser melhor solucionados com a utilização de técnicas de poda de elevação ou redução realizadas por profissionais especializados, fornecendo espaços verticais e eliminando o conflito com equipamentos urbanos (ABNT, 2013). 


\section{Qualidade arbóreo-arbustiva}

Os sinais de podas observados foram: 40,08\% com poda de elevação; $25,21 \%$ não possuía sinais de poda; $11,16 \%$ com podas de contenção; $10,74 \%$ com poda de redução; 9,50\% com poda de limpeza; $2,48 \%$ houve a retirada integral da copa; e $0,83 \%$ com poda sem objetivo evidente.

Foi observado necessidade de poda de condução em $21,49 \%$ do indivíduos, para condução de ramos-líderes e distribuição estrutural equilibrada dos galhos; poda de limpeza em $23,56 \%$, para remoção de galhos mortos ou danificados; e poda emergencial em 2,07\%, em indivíduos que foram verificados problemas de galhos que oferecem riscos imediatos a terceiros ou serviços de utilidade pública (ABNT, 2013).

Umas das finalidades da poda de elevação é a retirada de galhos que dificultem a passagem de pessoas e veículos pelas vias (PORTO; BRASIL, 2013). No município em estudo, a maioria dos indivíduos vegetais encontram-se em canteiros centrais, e, com o processo desordenado de urbanização no município, houve a implantação de quiosques informais nesses espaços destinados a comercialização de produtos. Para as arvores não oferecem "riscos" a esses quiosques, a prefeitura municipal realiza podas de levantamento sem apoio nas recomendações técnicas (Figura 6).

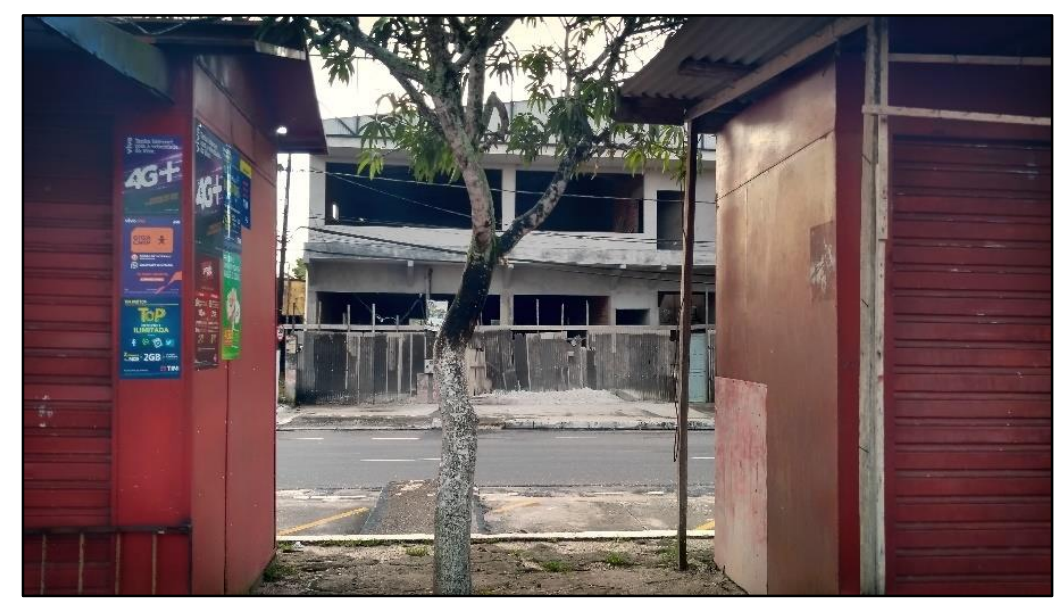

Figura 6. Mangueira plantada entre quiosques no canteiro central da Av. Barão de Capanema, em espaçamento de 1 metro da edificação.

Figure 6. Mango tree planted between kiosks in the central island of Barão de Capanema Avenue, spaced in 1 meter from the building.

Muitos problemas com a arborização urbana advêm da condução equivocada da poda, que, quando mal executada, pode gerar problemas com harmonia da copa, conflitos com fiação ou edificações e entrada de fitopatógenos.

Na pesquisa foi observado que 95,45\% das árvores portavam troncos sem inclinação, $3,72 \%$ tinham o tronco com inclinação, mas não interferindo em equipamentos urbanos ou vias, e $0,83 \%$ portavam troncos com inclinação e interferindo vias. Na figura 7 é possível observar 
uma mangueira com poda realizada de forma inapropriada para fornecer espaço ao quiosque localizado de forma irregular no canteiro central.

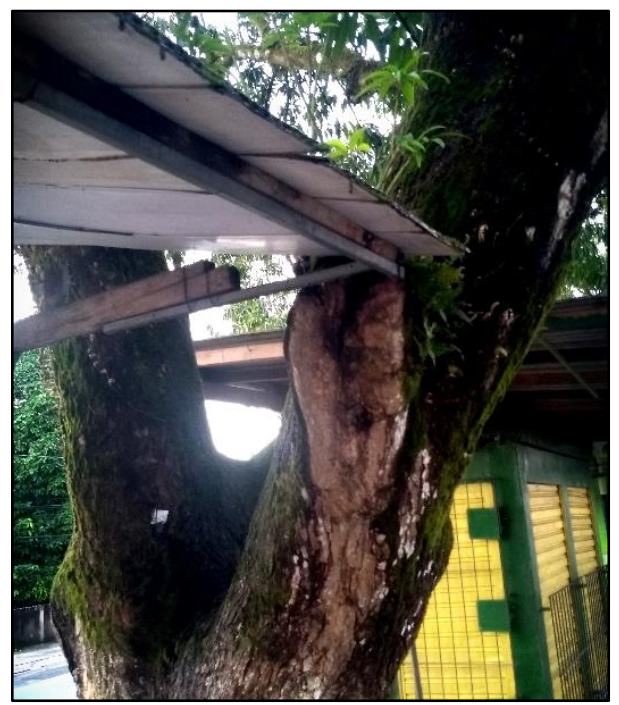

Figura 7. Mangueira plantada em canteiro central na Av. Barão de Capanema, com tronco fornecendo apoio a estrutura de um quiosque.

Figure 7. Mango tree planted in a central island at Barão de Capanema Avenue, with trunk providing support to the structure of a kiosk.

O estado do tronco se mostrou íntegro na maioria dos casos (85,59\%), não apresentando danos físicos ou fitossanitários, porém, problemas relacionados a vandalismo $(6,99 \%)$ e problemas com poda (compartimentalização) $(4,11 \%)$ foram identificados em algumas das árvores (Figura 8).

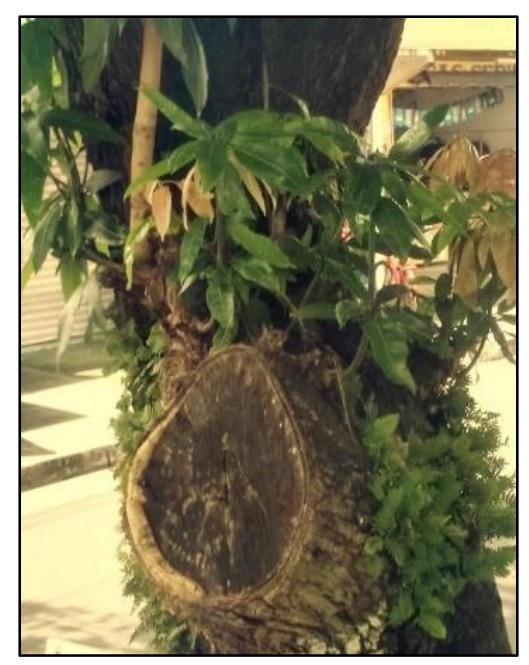

Figura 8. Problemas com compartimentalização em árvores Figure 8. Problems with tree compartmentalization

O processo de compartimentalização requer células em atividade para sua formação, e quando uma lesão no vegetal é realizada (podas ou vandalismos), as células no seu interior não 
possuem a mesma proteção ficando sensíveis aos ataques de patógenos (SEITZ, 1996). Segundo o mesmo autor, a compartimentalização é fundamental para o vegetal, evitando a dispersão da degradação da madeira a partir da superfície onde ocorreu o corte, esse processo exige um metabolismo ativo, sendo indicado a poda no início de períodos vegetativos.

Além disso, foi identificado uma árvore com tronco oco (Figura 9), e problemas com ramos codominantes $(3,70 \%)$.

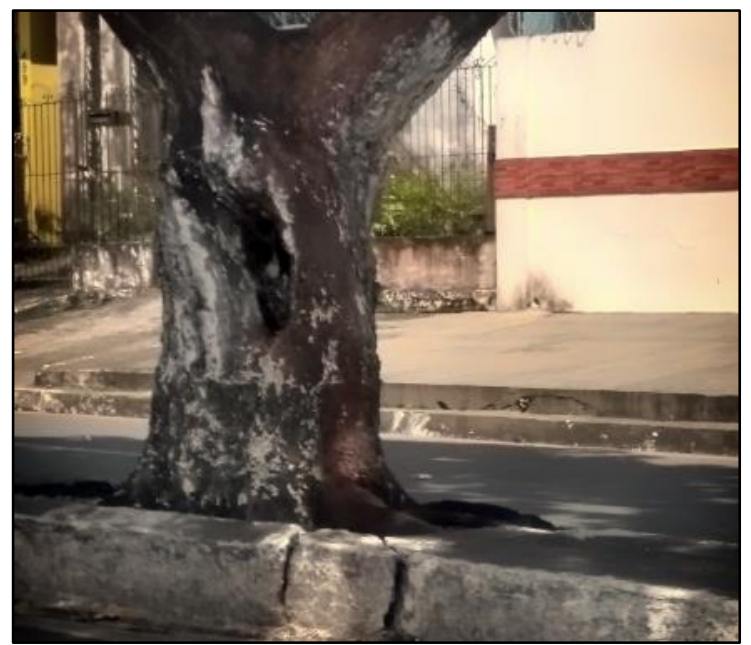

Figura 9. Árvores com o tronco oco na Avenida João Paulo II

Figure 9. Trees with hollow trunk at João Paulo II Avenue

Problemas relacionados à afloração das raízes em calçadas ou vias pavimentadas foi identificado em 29,34\% dos casos (Figuras 9 e 10), resultado de um planejamento insatisfatório em relação a implantação da vegetação nessas vias. Toda a extensão da Avenida João Paulo II possui problemas com afloração de raízes de mangueiras no canteiro central, o qual, possui menos de 0,5 metro de largura (Figura 10).

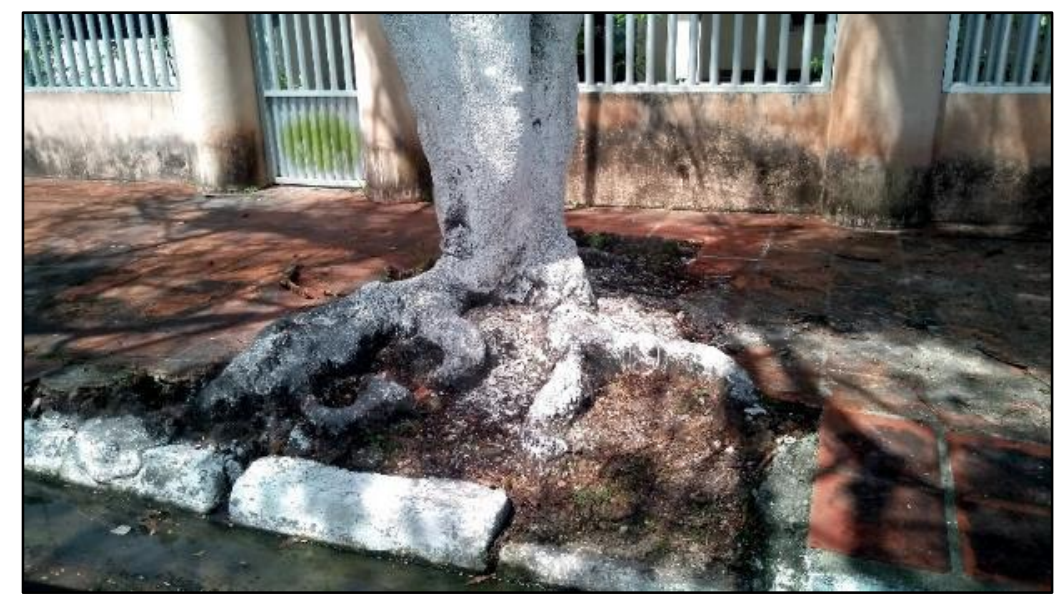

Figura 10. Problemas com afloramento de raízes em um Ipê Figure 10. Problems with root outcrop in an Ipê 
Apesar de grande parte das calçadas não apresentarem problemas relacionados ao afloramento de raízes no momento da coleta de dados, as mudas recém implantadas nas vias estudadas, todas de mangueiras, que representam $26,74 \%$ do total catalogado, se encontram em espaços inapropriados para o seu desenvolvimento ou apresentam o canteiro totalmente pavimentado por concreto.

A maioria dos indivíduos cadastrados na pesquisa possuem seu vigor médio e danos reparáveis $(22,22 \%)$. Caso os danos fossem facilmente reparáveis, os indivíduos eram classificados com vigor médio e se o vegetal não apresentasse problemas com interferências ou demonstrasse vitalidade, estes eram classificadas com vigor (Figura 10).

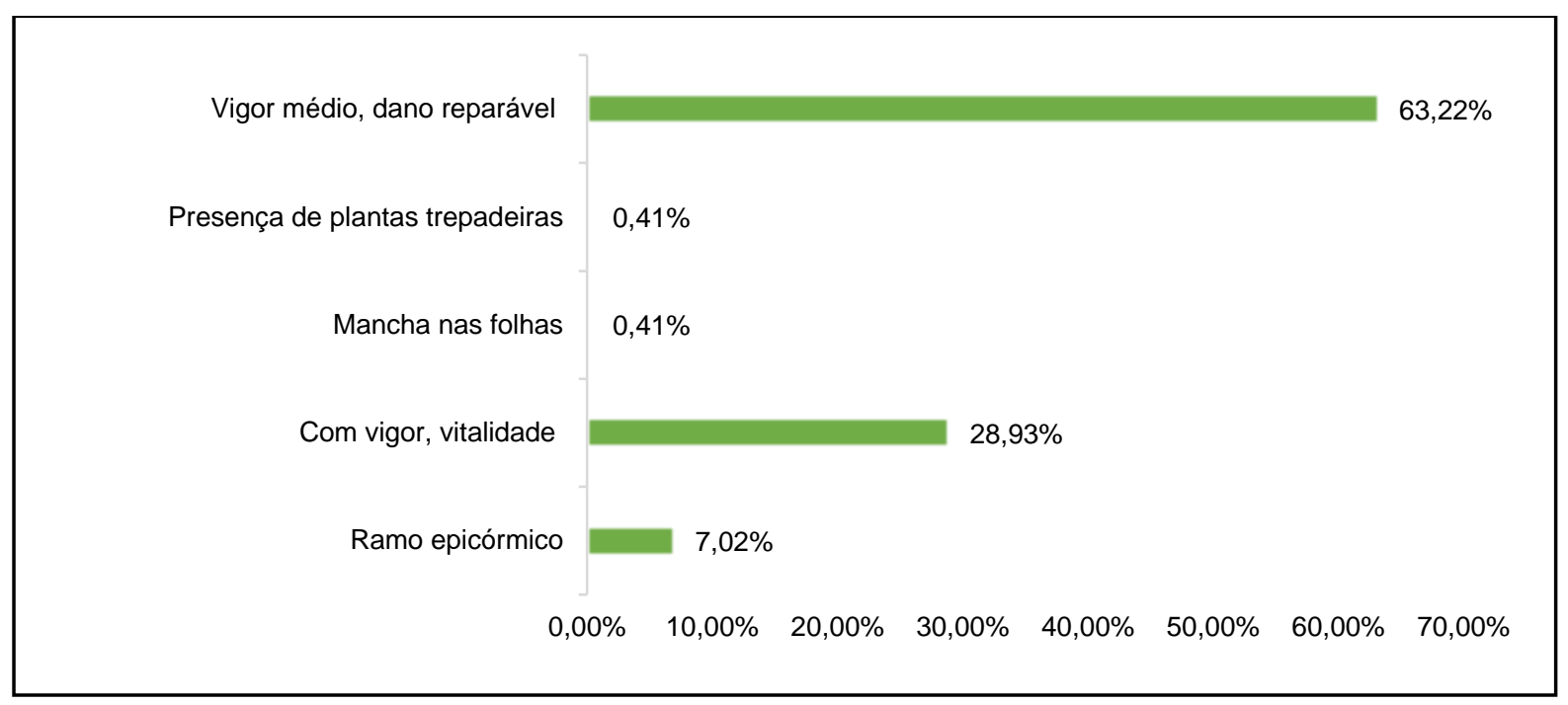

Figura 10. Diagnóstico fitossanitário arbóreo-arbustivo das principais vias de Capanema-Pará Figure 10. Arboreal-shrub phytosanitary diagnosis of the main roads in Capanema-Pará

Em alguns casos foi encontrado ervas de passarinho e manchas nas folhas, mas com baixa frequência na pesquisa. As manchas nas folhas pode ser resultado das várias pressões ocasionadas pelo meio, uma vez que as espécies que apresentavam tais características se encontravam em ambientes desfavoráveis ao seu crescimento. No ambiente urbano a vegetação fica exposta as adversidades do espaço, sofrendo pressões biológicas, químicas e físicas, que são alinhadas ao abandono das gestões públicas, resultando em danos à vegetação urbana (BARROS; ALBERTIN, 2013). Também foi identificado casos de brotações epicórmicas (6,99\%) (Figura 11).

Quando existe um desequilíbrio na árvore e a perda de galhos vitais é superior em relação à copa viva, ou quando as partes inferiores do vegetal recebem mais luz que as superiores, podem quebrar a dormência de gemas na casca do tronco gerando ramos ou galhos epicórmicos, sendo estes ligados apenas aos vasos formados no início de sua brotação (SEITZ, 1996). 


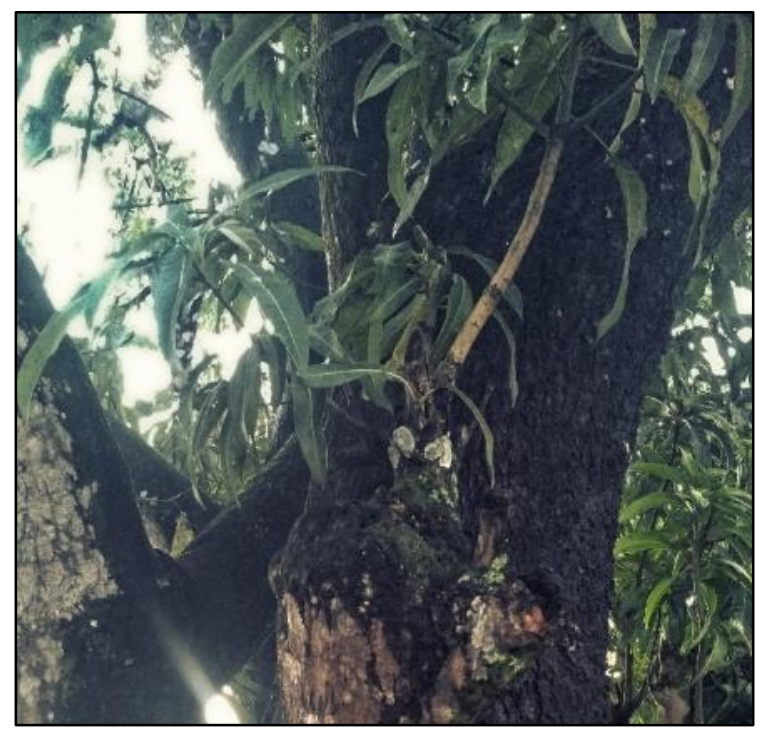

Figura 11. Vegetal com brotações epicórmicas

Figure 11. Plant with epicormic sprouts

Este problema pode surgi por má condução da poda. No município em estudo é visto muitos problemas com o processo de urbanização, dentre eles a implantação de quiosques (Figura 5 e 6) em canteiros centrais sem as devidas recomendações, essa implantação gera problemas a arborização, que sofre com podas conduzidas por profissionais incapacitados ou pelos próprios donos de quiosques. A condução equivocada faz com quem não ocorra o processo de compartimentalização, dessa forma podem surgi as brotações epicórmicas, estimulando a formação de uma nova copa, causando instabilidades e podendo provocar danos.

\section{CONCLUSÃO}

A arborização das principais vias do município de Capanema apresentou o predomínio de espécies exóticas ao ecossistema paraense, destacando as mangueiras (Mangifera indica L.), que representaram $61,32 \%$ na amostragem, a escolha desta espécie para arborização pode ser justificada por questões culturais, mesmo em condições de desacordo com as recomendações técnicas. O fícus (Ficus benjamina) foi a segunda espécie mais expressiva com 10,29\%, espécie inapropriada para o desenvolvimento em calçadas ou canteiros centrais, devido aos danos que as raízes podem provocar à infraestrutura.

A necessidade de poda e os conflitos das árvores decorre de problemas como a falta de planejamento da urbanização e da arborização. Foi visto necessidades de poda de condução, limpeza e emergencial. As podas emergenciais são principalmente em decorrência da falta de planejamento urbano, o apoio da fiação elétrica em galhos de árvores e a construção de 
quiosques utilizando as árvores como estrutura, sinalizam a importância de um melhor planejamento.

A maioria dos vegetais possui vigor médio, contudo as mudas recém plantadas (26,74\%) foram vistas em canteiros inferiores ao recomendado para essas espécies, podendo apresentar futuros danos à infraestrutura.

Se faz necessário a mobilização da esfera municipal para o fomento de decretos relacionados ao planejamento da arborização e melhor planejamento urbano.

\section{AGRADECIMENTOS}

Ao Programa Institucional de Bolsas de Iniciação Científica (PIBIC/UFRA)

\section{REFERÊNCIAS}

ASSOCIAÇÃO BRASILEIRA DE NORMAS TÉCNICAS. NBR 16246-1: Florestas urbanas manejo de árvores, arbustos e outras plantas lenhosas-p1: Poda. Rio de Janeiro, ABNT, 2013.

BARROS, E. F. S.; GUILHERME, F. A. G.; CARVALHO, R. S. Arborização urbana em quadras de diferentes padrões construtivos na cidade de Jataí. Revista Árvore, Viçosa, v. 34, n. 2, p. 287-295, 2010.

BARROS, R. de A.; ALBERTIN, R. Diagnóstico quali-quantitativo da arborização viária a partir da utilização da ferramenta street view. Geoingá: Revista do Programa de Pós-Graduação em Geografia, Maringá, v. 5, n. 2, p. 124-140, 2013.

BIAGOLINI, C.; LOURENÇO, R. W. Relação entre avifauna e plantas frutíferas em 10 parques lineares da cidade de São Paulo (Brasil). Conhecimento Interativo, v. 12, n. 2, p. 70-81, 2018.

DUARTE, T. E. P. N.; ANGEOLETTO, F.; SANTOS, J. W. M. C.; SILVA, F. F.; BOHRER, J. F. C.; MASSAD, L. Reflexões sobre arborização urbana: desafios a serem superados para o incremento da arborização urbana no Brasil. Revista em Agronegócio e Meio Ambiente, Maringá, v. 11, n. 1, p. 327-341, 2018.

Flora do Brasil. Jardim Botânico do Rio de Janeiro. Disponível em: http://floradobrasil.jbrj. gov.br/. Acesso em: 12 mai. 2020.

GONÇALVES, L. M.; MONTEIRO; P. H. da S.; SANTOS, L. S.; MAIA, N. J. C.; ROSAL, L. F. Arborização Urbana: a Importância do seu Planejamento para Qualidade de Vida nas Cidades. Ensaios e Ciência: Ciências Biológicas, Agrárias e da Saúde, Londrina, v. 22, n. 2, p. 128136, 2018.

GRISE, M. M.; BIONDI, D.; ARAKI, H. A floresta urbana da cidade de Curitiba-PR. Floresta, Revista Floresta, v. 46, n. 4, p. 425-438, jan. 2017.

HOPPEN, M. I.; DIVENSI, H. F.; RIBEIRO, R. F.; CAXAMBÚ, M. G. Espécies exóticas na arborização de vias públicas no município de Farol, PR, BRASIL. Revista da Sociedade Brasileira de Arborização Urbana, Curitiba, v. 9, n. 3, p. 173-186, 2014. 
IBGE - INSTITUTO BRASILEIRO DE GEOGRAFIA E ESTATÍSTICA. Arborização de vias públicas, 2010. IBGE, 2010.

INSTITUTO NACIONAL DE METEOROLOGIA. Normais climatológicas, 1981 - 2010. Brasília: INMET, 2018.

LEMOS, A. J. O Município de Belém: Relatório apresentado ao Conselho Municipal. Belém, 1903.

LOPO, D. Percepção, diagnóstico e gestão da arborização e áreas verdes urbanas nas cidades fronteiriças Brasil-Bolívia. Dissertação de Mestrado em Estudos Fronteiriços da Universidade Federal de Mato Grosso do Sul Campus do Pantanal, 2014.

MOTTER, N; MÜLLER, N. G. Diagnóstico da arborização urbana no município de TuparendiRS. Revista da Sociedade Brasileira de Arborização Urbana, Curitiba, v. 7, n. 4, p. 27-3, 2012.

MULLER, J. Orientações Básicas para Manejo da Arborização Urbana: Planejamento e Educação Ambiental. Porto Alegre: Ed. Famurs, 2002.

PAIVA, A. Aspectos da arborização urbana do Centro de Cosmópolis-SP. Revista da Sociedade Brasileira de Arborização Urbana, Curitiba, v. 4, n. 4, p. 17-31, 2019.

PORTO, L. P. M. P.; BRASIL, H. M. S. Manual de orientação técnica de arborização urbana de Belém: guia para planejamento, implantação e manutenção da arborização em logradouros públicos. Bélém: Universidade Federal Rural da Amazônia, 2013.

RABELO, L. K.; PIRES, E. C.; BAUMANN, S. S. R. T.; BRÍGIDA, C. A. S.; SILVA, J. B. S.; LIMA, P. S.; MAESTRI, M. P.; AQUINO, M. G. C. Espécies frutíferas na arborização urbana do município de Santarém, Pará. Revista Ibero Americana de Ciências Ambientais, v.10, n.3, p.335-341, 2019.

RUFINO, M. R.; SILVINO, A. S.; MORO, M. F. Exóticas, exóticas, exóticas: reflexões sobre a monótona arborização de uma cidade brasileira. Rodriguésia, Rio de Janeiro, v. 70, 2019.

SEITZ, R. A. A poda de árvores urbanas. Curitiba: FUPEF, 1996. 41 p.

SILVA, A. F. da; FORSBERG, M. C. S. Espécies exóticas invasoras e seus riscos para a Amazônia Legal. ScientiaAmazonia, Manaus, v.4, n.2, p.114-124, 2015.

SILVA, J. V. L.; SILVEIRA, R. L. L. Urbanização, Planejamento e Arborização: uma análise da cidade de Santa Cruz Do Sul/RS. Colóquio-Revista do Desenvolvimento Regional, Taquara, v. 17, n. 1, p. 161-180, 2020.

SILVA, M. E. P.; SANTOS, E. R. Diagnóstico e planejamento de desenvolvimento do território rural do nordeste paraense. Capanema: Fundação Socioambiental do Nordeste Paraense-FANEP, 2006.

SOUSA, V. F. O.; SANTOS, G. L.; RODRIGUES, M. H. B. S.; BARROSO, R. F.; BARBOSA, J. B.; FERNANDES, A. V. F. Percepção sobre qualidade da arborização urbana da cidade de Pombal, Paraíba. Revista Verde de Agroecologia e Desenvolvimento Sustentável, Pombal, v. 13, n. 3, p. 343-347, 2018. 